\title{
The Impact of Social Transformation on Chines Language Education Reform
}

\author{
Dongdong Fan \\ Literary College. Zhengzhou Normal University,Zhengzhou,450044, China \\ email: ddfan828@163.com
}

Keywords: Social transformation; Talents cultivation; Multi-cultures; Chinese language education

\begin{abstract}
With the implementation of the open and reform policy, great changes have occurred in many fields like politics, economy, thought and culture; our society has entered into a complete transformation period, which accordingly has caused new challenges and impact on education. Elementary education reform is one of the most important measures in the field of education in this new era. Chinese language education, a very important part, has been deeply influenced. This is the social background of the "Compulsory Chinese Language Curriculum Standard" formation and revision. The various value conflicts, the penetration of social core value system, and mix of multi-cultures will inspire educa Social transformation; Talents cultivation; Multi-cultures; Chinese language education tors to develop new ideas, hence face different challenges in this special period.
\end{abstract}

\section{Introduction}

While reform and opening up have brought the profound changes and impact on politics, economy, culture and social ideology, China has gradually entered a stage of comprehensive and accelerated social transformation. Some researchers and scholars believed that transition had broad sense and narrow sense. Broad sense refers to a complex, structural social transformation such as transition from the feudal despotism to the bureaucrat capitalism or liberal socialism, from the agricultural society to the industrial or modern information society; the narrow sense refers to transformation occurring at specific historical period. The current transformation is the most complicated, integrative one since 1980's. 1 It exhibits the progress being made from a high centralization in politics to democracy, from planned, state-owned economy to free-market economy, from conservative ideology to diversified ideology. China is under the development of modernization, economic globalization and culture diversity.

Education, a sensitive nerve of society, is facing the new challenges and crises the social transformation has brought. Chinses language Curriculum, as important part of education, is impacted fundamentally by the transformation as well. Social transformation is not only the background but also the motivation and dynamic mechanism of language education reform. Social economic development puts forward new demands for high-quality workers and creative talents. Chinese Language education system will have to make forceful and appropriate responses. Various value conflicts and multi-culture interleaving during the transition period will stimulate educators expanding ideas and standing various tests.

\section{Social and Economic Needs For High-Quality And Innovative Intelligence}

\section{Social Development Needs}

Social development in transition is mainly comprised of the transition from tradition to the modernization, including material aspects of modernization to system-level and then to concept-level. It manifests the wide use of information technology and the deeply rooted concept/acceptance of democracy and rule of law. 
The extensive application of information technology is the major indicator of entering the information age. In the process of social transformation of our country, the emergence and increasing popularity of computers and the Internet have a significant impact on the whole society. The volume of information, speed of information dissemination, and the extensive applications have been growing dramatically and brought unprecedented convenience to people's lives, work, and learning. However, those large amounts of information are the mix of richness, complexity, and sometimes biased and wrong views. This not only requires students to have strong capabilities of gathering information, but also has good judgmental skills, ability to effectively identify, extract, and process all kinds of information. By doing so, they will be able to quickly obtain accurate and effective information and never get lost.

Democracy and rule of law are the two other major indicators, as well as the important guarantee, of social progress. Because there are many unstable factors affecting social harmony, China is committed to building a socialist harmonious society. President $\mathrm{Hu}$ Jintao stated during the CPC symposium opening ceremony: "The socialist harmonious society we are committed to should feature democracy, the rule of law, fairness and justice, sincerity and vitality, stability and order, and harmonious coexistence for human and nature.” President Hu putting democracy and the rule of law in the first place fully reflected the important roles which democracy played in moving forward with social progress. What is democracy? What is the rule of law? According to many researches, democracy is a means for the people to choose their leaders and to hold their leaders accountable for their policies and conduct. The rule of law is a system in which the following four universal principles are upheld: the government and its officials and agents, as well as individuals and private entities, are accountable under the law. In addition to the government's devotion to protect people's rights and improve the laws and regulations, people's participation and supervision are more critical. This requires people to enhance the overall sense of democracy and ability to participate in the national affairs and decision-making.

\section{Economic Development Needs}

Economic development at the transition period is comprised of three components of transformation: the shift of economic system from a planned economy to a free-market economy; the shift of economic restructure from the three main industrial structures to the knowledge-based economy; the shift of economic growth mode from extensive economy to intensive economy.

In the period of social transition, planned economy has been shifting to socialist market economy. The free-market economy refers to a free price system. The socialist market economy is the combination of free-market economy and socialist system, which is under the macro-control by government and plays a fundamental role of allocating resources. Such a system and economy maximizes freedom, equality, competition, cooperation, the rule of law, and morality. As the free-market economy allows to make choice, exchange and cooperation on the voluntary basis, the exchange of equal values is engaged between subjects. Therefore, it requires ability to be subjective and willing to take the initiative and positive attitude to face the challenges of competition. In order to remain competitive in an invincible position, we must have a strong sense of competition, exploration, innovation, and willingness of carrying out new ideas and methods to deal with the new, emerging situations. Of course, there are also cooperation in the competitive process. We must enhance our social skills. The principle of market economy is the mutual benefit during cooperation. Even though materialistic, people need to respect and abide the law, regulation, and morality in order to remain competitiveness in the market in the long run. So, in the pursuit of personal interests, people should also strengthen moral self-cultivation and awareness of law in order to run business freely without breaking the law.

Knowledge-based economy becomes more and more compelling during the adjustment of economic structure. Comparing to the agricultural age in which inheritance and accumulation of knowledge were the theme, and industrial age which was characterized by popularization and 
expansion of knowledge, the knowledge-based economy era is featured with creation and innovation. Knowledge-based economy relies on the innovation, dissemination, and application of knowledge of which human being is the only carrier. Therefore, in order to adapt to knowledge-based economy situation, we need to motivate our inspiration of innovation and practical ability. The same will be applied when to achieve the shift from extensive to intensive economy: Extensive economy depends on the increase in the amount of production factors and investment to expand the scale of production to achieve growth, while the intensive economy depends on the improvement of quality and efficiency. This new way of low energy consumption, low costs, high economic efficiency wouldn't be achieved without innovative intelligence.

\section{Education Requirements}

Educational aim is to set up general requirements, quality specifications, and education objectives for schools at all levels and to address the questions like "whom we educate people for?" or "what type of person we educate people to become?” It reveals the standards of education in a given period. The current education aims to implement quality-oriented education, which attaches to people's thinking, moral quality, ability, personality development, and physical and mental health.2 The progressive development of social economy has raised new requirements. It is unavoidable for education, as a conscious human activity, to meet those requirements. So, China has made the decision to deepen education reform, promote quality-oriented education nationwide, and focus on the development of student's inspiration and ability. In the beginning of the new century, China launched a new round of curriculum reform: re-structuring the curriculum system and content in the basic education for a newer generation to adapt to the needs of society and social development.

Chinese language education also closely follows the pulse of the times. For instance, the revision of Language Curriculum Standards adheres to the direction of curriculum reform, which upholds "the implementation of people-oriented scientific concept of development in the field of basic education". 3 In term of curriculum design, there are three dimensions: emphasis on knowledge and ability; highlight of methodology and process; involvement of attitude and values into all aspects of language education. Those three dimensions are not only the extension of traditional "double-base" (basic knowledge and basic skills) but also the move to cope with emerging problems. Meanwhile, language curriculum is clearly described as "a comprehensive and practical course to learn how to use of language.” Integrity and practicality emphasize the demands on new prospect, open mind, and creative thinking through the progress of economic globalization and social informatization. The curriculum content highlights the needs from basic skills such as "literacy”, "reading”, "writing”, and "oral communication" to "comprehensive ability of studying" and so on. It strengthens the ties within many aspects of language courses and across others outside of language courses to promote the comprehensive and harmonious development of students. In the course of implementation, attention has been paid to cultivate student's initiative and creativity and to inspire student's innovation, practical ability, curiosity, and desires for knowledge. Teachers should create an open, cooperative, and exploratory learning environment for students to develop their ability and skills of thinking, imagination, creativity, analysis, and problem-solving. Meanwhile, teachers should penetrate the concept of information technology education to help laying a good foundation for students to easily adapt to the modern society.

\section{Value Crisis and Call for Humanistic Education}

During the transition, the rapid development of economy and technology has brought both good progress and negative impact to all human beings. Wealthy in material doesn't mean the richness in spiritual world. Value crisis and moral perversity are imminent. Therefore, we should rebuild system of moral and believes and use humanities to resist the adverse effects of lack of humanistic concerns, distorted values, and wide-spread utilitarianism. Language course is a course full of humanities connotation. If teachers are able to unify the instrumentality and humanity of language course 
perfectly, it would strengthen the humanistic care, recover the lost values, and restrain spread of utilitarianism. It certainly would bring a broad and profound impact to students.

\section{Highlights of Humanistic Care}

People interpreted humanism differently depending on the time they lived. In ancient times, "humanism" was contrary to "astronomy". The traditional humanism was comprised of theories such as group consciousness, social personality, and unity of human and nature. In modern society, "humanism" is contrary to "science". The modern humanism advocates the idea of "people first". By synthesizing understandings of traditional and modern humanism, we could interpret the humanism as the representation of highest human values and the meaning of existence. It moves people forward to truth, goodness and beauty. However, developing humanistic spirit is a slowly progressive process. It is difficult to exhibit an immediate result. Even worse, humanism doesn't seem to be practical in today's society. It is why humanism continues getting lost and decentralized.

Influenced by various ideological trends, the nature of Chinses subject has been controversial. There are two major points of view: instrumentalism and humanism. The people who hold instrumentalism point of view believe that language education should develop student's language proficiency such as basic skills of listening, speaking, reading and writing. The people who hold humanism point of view suggest that language education should focus on literacy in order to advance and enrich Chinese culture and ethnic characteristics. Each of these two views has its own theory behind, but also is biased. In fact, the distinction between language proficiency and literacy is not clear-cut. Both are extremely important to be part of language education. Language education has to break through deep scientism and pragmatism, challenge the traditional examination-oriented education system, and overcome the shortcomings caused by the neglect of humanistic spirit. The goal of contemporary language education is to build characteristics, gain the knowledge and skills, and lift the spirit of innovation and creativity, and lay a solid foundation for better life. 4

\section{Integration of Values}

Values refer to "the belief, orientation, pursuit, and standards for social phenomena. It is the perception of human behavior, life, wealth, honor, character, contribution, enjoyment, rights, responsibilities, person-to-person interaction, and person-to-society interaction." 5 Social transformation is a transition from one social state to another, in which a new social system begins emerging and the old one hasn't been cleaned up yet. It often causes a conflict between traditional values and modern values. The conflict reveals the collision and contradiction of individual values and society values. It becomes important for language education to focus on the integration of various values and provide guidance to adolescents.

Chinese traditional value system is dominated by a social standard which asks individuals subordinate to the group or society. In contrast, Western value system is an individual standard which respects and protests individuals and their lives, freedom, and private property. With China's economic development and international exchanges increasingly widespread, Western life style and values inevitably flood in. Our traditional values of collectivism have been challenged by western individualism. Chinese language education should inherit and carry on the fine characteristics of traditional culture, take advantage of core value system and ideals of socialism, and promote the patriotism and contemporary spirit of innovation and reform. Meanwhile, Chinese language education should also respect student's unique experience in the learning process. In other words, language education is not to separate individual from group, rather to seek the common ground between different value systems so that students adapt good ethnics and discard bad ones.

\section{Containment of Utilitarianism}

"Righteousness" means the spiritual pursuit, such as high moral standard, lofty ideals, and determined ambition; "profitableness” indicates the material interests, particularly personal interests. 
Traditionally there were two kinds of understanding for righteousness and profitableness: first at all, people thought highly of the righteousness and utterly despised profitableness, so-called by Confucius "gentlemen know righteousness, the villain known only profit" or "rather starve to death than lose my chastity". However, ancient education in our country seemed to display a strong characteristics-utilitarianism. An old saying of "Learning brings us everything" gives a best interpretation that people who lived in feudal society could be promoted to a higher rank or change their identity through reading. With the development of market economy, principle of utilitarianism has been widely accepted not only in economic field but also in other areas. Therefore, under the influence of traditional and contemporary utilitarianism, it becomes more and more critical for language education to keep the fine tradition of focusing on learning, accumulation and inspiration and also to aim to correct short-sighted behaviors and suppress the eager for instant success and benefit.

Utilitarianism is namely the effectiveness and benefit. Pursuit of utilitarian is blameless. However, if the interest in material benefit surpasses the interest in moral spirit, tendency of utilitarianism would be a concern because the flood of utilitarianism has negative impact on not only individual growth but also China's socialist construction.

Utilitarianism in language education appears as the unilateralism of education objectives. Education should pay attend to people's physical and mental development. However utilitarian education has the following features: 1) emphasizes one-sidedly on intellectual development and contempt for all-round development of moral, physical, aesthetics and labor education; 2) concerns about the examinations and neglects the long-term objectives; 3) simplifies classroom activities and minimizes the social practices; and 4) focuses on the inculcation of knowledge and ignores the penetration of humanistic spirit. For example, the exam-oriented education has paid attention to score and graduation rate, which make students and teachers do whatever the examination takes and result in a heavy academic burden on students. We mistakenly believe that the ultimate goal of education is to force the student studying, gain higher diploma, find a better job and make a good living. The student's childhood is ruthlessly stripped by the utilitarianism of education. Language education has reiterated the fine tradition of "Righteousness prior to benefits" from all aspects and broken the shackles of utilitarianism.

\section{Acknowledgements}

In this paper, the research was sponsored by the 2012 Henan Province Soft Science Research Projects (Project No. 132400410833).

\section{References}

[1] Yang Xiaowei, "Methodology of School Reform in the Period of Social Transformation” [D]. East China Normal University, 2002.

[2] "Decision of the CPC Control Committee and the State Council on Deepening Educational Reform and Promoting Essential-qualities-oriented Education”, CPC Announcement, [1999] No. 9.

[3] Zhu Muju, Xu Huijuan. “Interview on the Ten-year Basic Education Curriculum Reform”. People’s Education Press, 2011 (18).

[4] Xu Xuxiu. "Knowledge-based Economy and Chinese Essential-qualities-oriented Education” (II) [J], Middle-school Chinese Curriculum Review, 1999 (07)

[5] Wang Yumao, “New Research on Philosophy of Value” [M], Shaanxi People’s Education Press, 1993. 